\title{
Correction to: Occult bacteremia etiology following the introduction of 13-valent pneumococcal conjugate vaccine: a multicenter study in Spain
}

\author{
Susanna Hernández-Bou ${ }^{1}$ • Borja Gómez ${ }^{1}$ Santiago Mintegi ${ }^{1}$ · Juan J. García-García ${ }^{1}$ On behalf of the Bacteraemia \\ Study Working Group of the Infectious Diseases Working Group of the Spanish Society of Paediatric Emergencies \\ (SEUP)
}

Published online: 21 June 2018

(C) Springer-Verlag GmbH Germany, part of Springer Nature 2018

Correction to: European Journal of Clinical Microbiology \& Infectious Diseases

https://doi.org/10.1007/s10096-018-3270-2

The names of the following three authors were inadvertently removed during the production of the original article. The names of the authors are correctly captured here.

Borja Gómez

Santiago Mintegi

Juan J. García-García

The original article has been corrected.

The online version of the original article can be found at https://doi.org/ 10.1007/s10096-018-3270-2

Susanna Hernández-Bou

shernandez@sjdhospitalbarcelona.org

Paediatric Emergency Department, Hospital Sant Joan de Déu Barcelona, Passeig Sant Joan de Déu 2, Esplugues de Llobregat, 08940 Barcelona, Spain 